\title{
TRANSFER PENGETAHUAN NILAI BARANG RONGSOKAN UNTUK BENGKEL SAMPAHQU - TANGERANG SELATAN
}

\author{
Rosehan $^{1}$, Helena Juliana Kristina ${ }^{2}$, Ahmad $^{3}$ dan Suraidi $^{4}$ \\ ${ }^{1}$ Prodi Teknik Mesin, Universitas Tarumanagara \\ Email: rosehan@ft.untar.ac.id \\ ${ }^{2}$ Prodi Teknik Industri, Universitas Tarumanagara \\ Email: julianak@ft.untar.ac.id \\ ${ }^{3}$ Prodi Teknik Industri, Universitas Tarumanagara \\ Email: ahmad@ft.untar.ac.id, \\ ${ }^{4}$ Prodi Teknik Elektro, Universitas Tarumanagara \\ Email: suraidi@ft.untar.ac.id
}

\begin{abstract}
In the concept of circular economy, paradigm of garbage as something that has a meaning (material recovery) so as to lower production costs and save natural resources that are not renewable and maintain the environment. By using circular economy principle, where the value of products and materials are maintained and utilized for as long as possible, so that landfill can be limited as small as possible. In Indonesia itself, there are several ways of collecting electronic waste from community sources, such as channeled through dropbox and Waste Bank for recycling. In unraveling the problem of waste, there must be social and economic institutions that cooperate with each other in their activities, for the sustainability of the movement in the community, both social movements and social engineers in changing the paradikma of waste management in the community. Because household electronic waste from waste banks is almost always present in every weighing. The knowledge of workers in lapak is very minimal to ascertain whether the goods can still function if repaired or must be channeled for recycling. Therefore, SampahQu intends to set up a small workshop in lapaknya for the management of electronic waste from households, which will try to invite teenagers in their villages and participants of the SampahQu network, to participate in this activity, in the hope as one way to foster environmental concern to them. The solution offered by the PKM team to SampahQu Bp Posma is to make an approach to the participants to build their internal motivation first, that garbage has a high value if it can be managed correctly, while supporting the Reuse and Recovery program, by transferring knowledge of the value of junk goods. This activity is realized in the form of a workshop class program SampahQu.
\end{abstract}

Keywords: Participation, Knowledge Transfer, Junk, Electronic Waste, Circular Economy

\begin{abstract}
ABSTRAK
Dalam konsep circular economy, paradigma sampah sebagai sesuatu yang mempunyai arti (material recovery) sehingga mampu menurunkan biaya produksi dan menyelamatkan sumber daya alam yang tidak terbarukan serta menjaga lingkungan. Dengan menggunakan prinsip circular economy, dimana nilai produk dan material dijaga dan dimanfaatkan selama mungkin, sehingga timbunan sampah dapat dibatasi sekecil mungkin. Di Indonesia sendiri, ada beberapa cara pengumpulan sampah elektronik dari sumber masyarakat, seperti disalurkan melalui dropbox dan Bank Sampah untuk di daur ulang. Dalam mengurai masalah sampah harus ada lembaga sosial dan ekonomi yang saling bekerjasama dalam kegiatannya, demi keberlanjutan gerakannya di masyarakat, baik gerakan sosial ataupun perekayasa sosial dalam mengubah paradikma kelola sampah di masyarakat. Dikarenakan sampah elektronik rumah tangga dari bank sampah hampir selalu ada di setiap penimbangan. Pengetahuan pekerja di lapak sangatlah minim untuk memastikan apakah barang - barang rongsok itu masih bisa berfungsi jika diperbaiki ataukah harus disalurkan untuk didaur ulang. Oleh karena itu, SampahQu bermaksud mendirikan bengkel kecil di lapaknya untuk pengelolaan sampah elektronik dari rumah tangga, yang dimana akan mencoba mengajak orang muda di sekitar lapak dan partisipan jejaring SampahQu, untuk ikut dalam aktivitas ini, dengan harapan sebagai salah satu cara untuk menumbuhkan kepedulian lingkungan kepada mereka. Solusi yang ditawarkan tim PKM kepada SampahQu Bp Posma adalah membuat suatu kegiatan pendekatan kepada para partisipan untuk membangun motivasi internal mereka lebih dulu, bahwa sampah punya nilai yang tinggi kalau bisa dikelola dengan benar, sekaligus mendukung program reuse dan recovery, dengan melakukan transfer knowledge nilai barang rongsokan. Kegiatan ini direalisasikan dalam bentuk program kelas bengkel SampahQu.
\end{abstract}

Kata Kunci: Partisipasi, Transfer Pengetahuan, Barang Rongsok, Sampah Elektronik, Ekonomi Sirkular

\section{PENDAHULUAN}

E-waste dapat diartikan sebagai barang barang elektronik yang sudah tidak dipakai, rusak atau sudah tidak diinginkan karena sudah menjadi barang yang usang dan perlu dibuang. Alat 
elektronik yang tidak terpakai cepat atau lambat akan berakhir di tempat pemrosesan akhir seperti landfill atau insinerator, dimana mereka akan mengeluarkan material beracun ke udara, tanah, dan air. Di berbagai tempat di negara maju, pengelolaan limbah elektronik yang baik sudah mulai dicoba untuk diterapkan dan digalakkan. Salah satu kegiatan yang bisa dilihat adalah programprogram pengumpulan limbah elektronik yang dijalankan oleh berbagai macam pihak. Di Indonesia sendiri, ada beberapa cara pengumpulan sampah elektronik dari sumber masyarakat, seperti disalurkan melalui dropbox dan Bank Sampah untuk di daur ulang. Daur Ulang mengandung arti yang sangat luas, yang sekarang ini lebih cenderung diartikan sebagai suatu cara untuk memisahkan antara berbagai sampah dan mengolahnya kembali dalam suatu sistem industri. Sistem terdiri dari perusahaan-perusahaan yang melakukan aktivitas mengumpulkan, memisahkan dan mengolah hasil buangan, sehingga dapat digunakan kembali untuk kepentingan lain. Organisasi yang menjalankan fungsi ini dapat berasal dari swasta atau melibatkan kerjasama dengan pemerintah. (Djajadiningrat et al., 2014).

Di dalam PERPRES NO 97 thn 2017 yang berisi tentang kebijakan dan strategi pengolahan sampah, mentargetkan sampai thn 2025, terjadi penanganan sampah $70 \%$ dan pengurangannya sampai $30 \%$. Hal ini dapat dilakukan dalam konteks pengelolaan sampah yang menggunakan prinsip 3 R: Reduce, Reuse dan Recycle, atau pembatasan guna ulang atau daur ulang, yang menjadi pokok utama dalam UU No 18 thn 2008 tentang Bank Sampah, yang diperkuat dalam Peraturan Pemerintah No 81 thn 2012 tentang Pedoman Pelaksanaan Program Pengelolaan Sampah Kota dan Sampah Sisa Rumah Tangga. Program bank sampah yang sudah ada di Indonesia dapat digunakan sebagai salah satu pintu masuk terwujudnya reverse logistic rantai pasok manufaktur berkelanjutan karena program bank sampah adalah praktisnya dari penerapan konsep hubungam ekonomi dan ekologi. (Helena, 2014)

Berdasarkan nilai ekonomisnya, sampah elektronik dikelompokan menjadi tiga kategori, yaitu sampah elektronik dengan nilai ekonomis tinggi, sedang, dan rendah (Namias 2013). Nilai ekonomis mengacu pada banyaknya kandungan logam mulia yang terdapat pada sampah elektronik di mana semakin banyak kandungan logam mulia, maka semakin tinggi nilai ekonomisnya. Menurut Direktorat Pengelolaan Sampah Kementrian Lingkungan Hidup dan Kehutanan (2017), Prinsip 5R (rethink-reduce-reuse-recycle-recovery) merupakan prinsip pembangunan berkelanjutan dalam pengelolaan sampah yang mengedepankan konsep sampah sebagai alternatif material recovery dan circular economy melalui pengelolaan sampah yang terintegrasi dan berwawasan lingkungan. Dalam konsep circular economy dibangun paradigma sampah sebagai sesuatu yang mempunyai arti (material recovery) sehingga mampu menurunkan biaya produksi dan menyelamatkan sumber daya alam yang tidak terbarukan serta menjaga lingkungan. Dengan menggunakan prinsip circular economy, dimana nilai produk dan material dijaga dan dimanfaatkan selama mungkin, sehingga timbunan sampah dapat dibatasi sekecil mungkin. Inti dari circular economy adalah menyeimbangkan aspek lingkungan dan ekonomi, sehingga dapat dijalankan bersama secara berkelanjutan. Semakin mahalnya sumber daya alam, sedangkan ekonomi harus tetap tumbuh, maka segala sesuatu nilai sumber daya ekonomi, termasuk yang sudah menjadi sampah, harus dimanfaatkan, agar ketika masa pakainya habis dapat di daur ulang dan di manfaatkan kembali berkali-kali, oleh industri lain. (Arief, 2018).

Selain itu keberadaan konsep circular economy juga didukung oleh konsep produksi bersih. Konsep dari produksi bersih bukan hanya mengurangi waste, melainkan memberikan saran dan kemungkinan untuk menggunakan waste sebagai sumber daya (Gujarat, 2016). Prinsip-prinsip dalam produksi bersih diaplikasikan dalam bentuk kegiatan yang dikenal sebagai 4R (Standtek, 2017), meliputi: 
1. Reuse, atau penggunaan kembali adalah suatu teknologi yang memungkinkan suatu limbah dapat digunakan kembali tanpa mengalami perlakukan fisika/kimia/biologi.

2. Reduction, atau pengurangan limbah pada sumbernya adalah teknologi yang dapat mengurangi atau mencegah timbulnya pencemaran di awal produksi misalnya substitusi bahan baku yang ber B3.

3. Recovery, adalah teknologi untuk memisahkan suatu bahan atau energi dari suatu limbah untuk kemudian dikembalikan ke dalam proses produksi dengan atau tanpa perlakuan fisika/kimia/biologi.

4. Recycling, atau daur ulang adalah teknologi yang berfungsi untuk memanfaatkan limbah dengan memprosesnya kembali ke proses semula yang dapat dicapai melalui perlakuan fisika/kimia/biologi.

Komunitas juga selalu memiliki banyak kepentingan dan pelaku, dan berkaitan dengan entitas entitas lain dalam skala yang berbeda (Susan \& Myers, 2014). Orang/lembaga atau partisipan yang bergabung dalam komunitas bank sampah, biasanya mempunyai minat, nilai dan keyakinan bahwa ada nilai ekonomi sosial yang didasarkan pada prinsip kebaikan bersama dari sampah yang dikelolanya, bagi kepentingan bersama anggota masyarakat dan lingkungan di sekitarnya. Komunitas ini membutuhkan partisipasi aktif dari penggurusnya ataupun relawan masyarakat untuk dapat berkelanjutan. Dalam mengurai masalah sampah harus ada lembaga sosial dan ekonomi yang saling bekerjasama dalam kegiatannya, sementara kelembagaan pengelolaan sampah mutlak harus ada demi keberlanjutan gerakannya di masyarakat, baik gerakan sosial ataupun perekayasa sosial (social engineering) dalam mengubah paradikma kelola sampah di masyarakat (Asroel, 2019).

SampahQu-Bp Posma ingin memberdayakan orang muda di sekitar lapak dan jejaring SampahQu. Dikarenakan sampah elektronik rumah tangga dari bank sampah hampir selalu ada di setiap penimbangan, sedangkan pengetahuan pekerja di lapak sangatlah minim untuk memastikan apakah barang - barang rongsok itu masih bisa berfungsi atau tidak. Jika barang rongsok masih bisa berfungsi seharusnya dicoba perbaiki dulu sebelum disalurkan untuk didaur ulang. Oleh karena itu, SampahQu bermaksud mendirikan bengkel kecil di sekitar lapak. Bengkel kecil ini akan digunakan untuk pengelolaan sampah elektronik dari rumah tangga, yang mana akan mencoba mengajak remaja di sekitar lapak dan partisipan jejaring SampahQu, untuk ikut dalam aktivitas ini. Harapan dari keberadaan bengkel ini, nantinya sebagai salah satu cara untuk menumbuhkan kepedulian lingkungan kepada masyarakat sekitar lapak. Solusi yang ditawarkan tim PKM Jurusan Teknologi Industri Untar adalah membuat suatu kegiatan pendekatan kepada para partisipan untuk membangun motivasi internal mereka lebih dulu, bahwa sampah punya nilai yang tinggi kalau bisa dikelola dengan benar, sekaligus mendukung program reuse dan recovery, dengan melakukan transfer knowledge nilai barang rongsokan. Kegiatan ini direalisasikan dalam bentuk program kelas bengkel SampahQu. Transfer knowledge/transfer pengetahuan adalah suatu strategi sistematis dan bertujuan untuk menangkap pengetahuan kritis dari personel kunci/pengajar untuk disimpan dan dibagikan kepada partisipan dalam komunitas.

\section{METODE PELAKSANAAN PKM}

Tahapan - tahapan pelaksanaan PKM adalah sebagai berikut:

1. Membuat WAG PKM untuk persiapan dan komunikasi, dan diskusi awal.

2. Mencari dan Menghubungi para calon partisipan remaja baik yang berdomisili di sekitar lapak (dibantu Bp Posma) dan partisipan dari jejaring wag SampahQu. 
3. Menyusun Role Play tim PKM dan Mitra. Role play adalah suatu strategi yang dipersiapkan tim PKM untuk kelancaran pencapaian kegiatan transfer knowledge dalam kelas. Role play dapat dilihat pada Tabel 1.

4. Membuat Rencana Materi dan Modul untuk membangun motivasi untuk partisipan Bengkel SampahQu, dan materi Transfer Knowledge Nilai Barang Rongsokan, yaitu: mempelajari fisik, kegunaan, cara kerjanya, mempelajari kerusakan, membuat keputusan; perbaikan atau kanibal, pertimbangan sisi ekonomis perbaikan atau kanibal

5. Mendata alat yang dibutuhkan dan serah terima alat dari tim PKM kepada mitra:

Multi tester seri YX-360TR, obeng set 7pcs, tang set 5pcs, kunci ring pas tekiro 11pcs, test pen, kunci inggris 12 inchi, timah, pasta solder dan sedotan timah, dan solder. Masingmasing alat disedikan 3 set.

6. Mendata partisipan. Data deskripsi partisipan dapat dilihat pada Tabel 2.

7. Membuat jadwal pertemuan. Jadwal pertemuan kelas dan rencana kegiatan rinciannya dapat dilihat pada Tabel 3.

8. Membuat WAG Kelas Partisipan untuk proses komunikasi kelas selama PKM.

Selama kegiatan PKM, untuk mempermudah menyampaian informasi, pengendalian aktivitas kelas guna mewujudkan transfer knowledge, maka dibuat wag kelas untuk kebutuhan komunikasi tim PKM, mitra dan partisipan kelas.

9. Membuat dokumentasi kegiatan.

Selama kegiatan kelas, didokumentasikan oleh tim PKM. Gambar 1. Kelas pertemuan 1 diadakan untuk menyamakan persepsi antara tim PKM dengan partisipan kelas mengenai yang dimaksud dengan transfer pengetahuan barang rongsok yang akan dilakukan dalam praktik. Penyamaan persepsi ini merupakan salah satu strategi yang dibuat tim PKM untuk kelancaran aktivitas kelas nantinya. Gambar 2. Kelas praktik, gambar 2, Anggota Tim PKM Untar memberikan contoh, cara dan penjelasan untuk memperbaiki sampah eletronik rongsokan.

10. Pemberian motivasi.

Tim PKM menyadari, keragaman individu/partisipan dalam kelas. Mulai dari keragaman tingkat pendidikan, ekonomi dan status sosial mereka di komunitas. Oleh karena itu untuk mendukung proses transfer knowledge, tim PKM merancang strategi sistematis lewat pemberian modul motivasi dan kata-kata motivasi, baik yang diberikan oleh tim PKM maupun e-poster kata-kata motivasi yang diberikan oleh partisipan kelas, untuk dinikmati bersama-sama. Selain itu juga dibuat dan disebar e-poster patuh protocol kesehatan selama kegiatan kelas praktik. Strategi ini diharapkan mampu menumbuhkan saling kepercayaan dalam tim kerja. Melalui bahasa bersama yang dimiliki antar individu, dapat memfasilitasi dan memotivasi transfer pengetahuan serta menciptakan proses pengaruh sosial yang positif (Blumenberg et al, 2009). Interaksi umum dan sering memainkan faktor penting untuk pelaksanaan proses transfer pengetahuan di mana hubungan antara individu dibangun dan mengurangi batasan dan hambatan dalam mentransfer pengetahuan. Keberhasilan transfer pengetahuan dapat dicapai hanya jika hubungan saling percaya antara kedua mitra tercapai, tercipta dan keseimbangan yang tepat antara transfer pengetahuan baru dan pelestarian pengetahuan yang ada. (Martinkenaite, 2012)

11. Evaluasi Hasil Kuesioner Kegiatan

Setelah kegiatan kelas, partisipan dihimbau untuk memberikan informasi kepada admin, mengenai progress pengetahuan yang didapatkannya setelah aktivitas kelas praktik dilakukan. Evaluasi dilakukan dengan penyebaran form kuesioner menggunakan google form. 


\section{Gambar 1}

\section{Pertemuan Kelas Online}
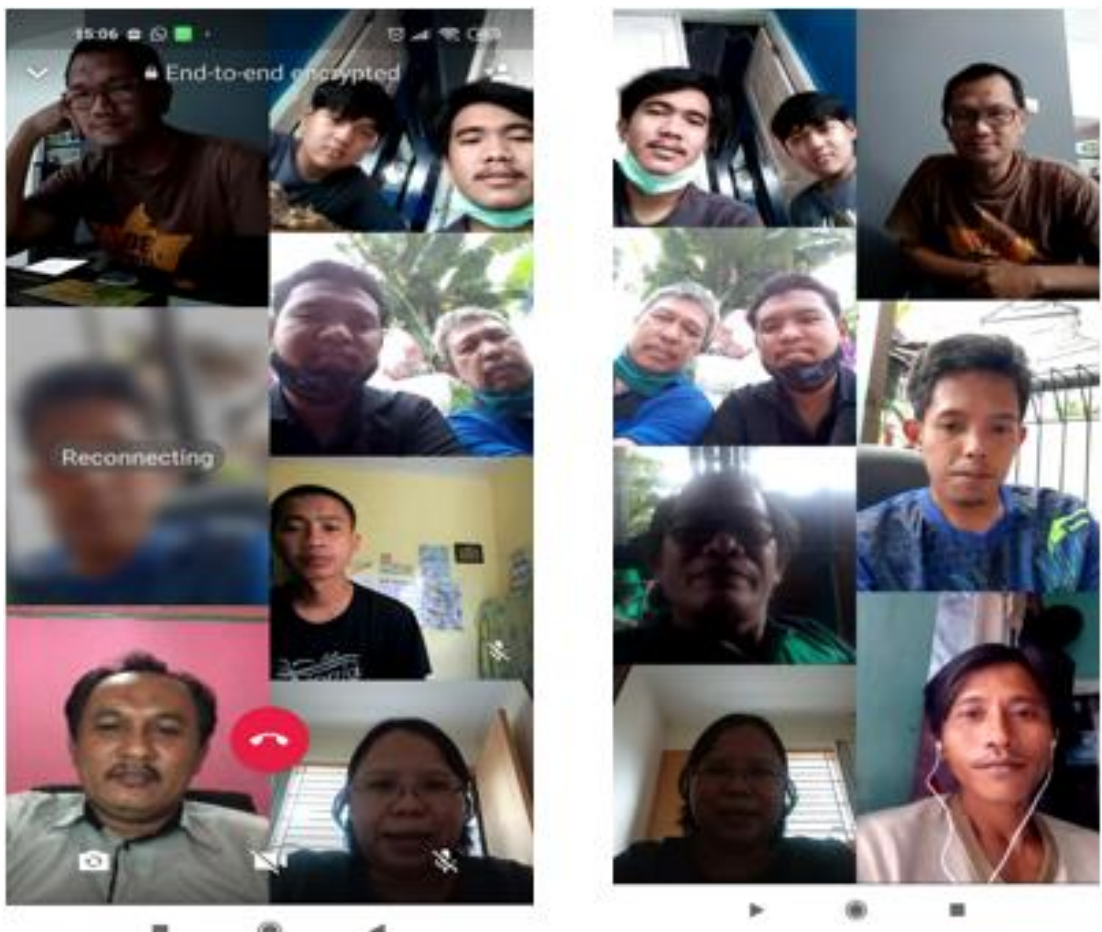

\section{Gambar 2}

Kelas Praktik

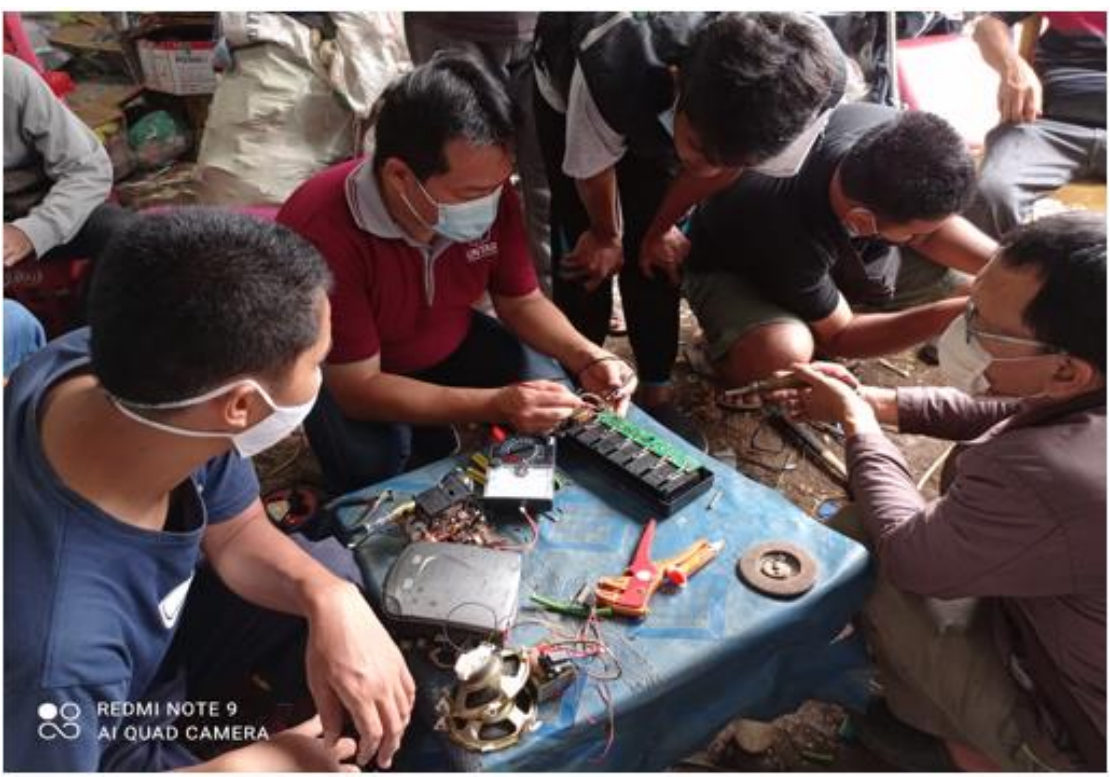

Tabel 1

Role Play Tim PKM dan Mitra

\begin{tabular}{llll}
\hline No & Nama & Keterangan role play & Instansi \\
\hline 1 & Rosehan & Pengajar Utama & Teknik Mesin UNTAR \\
2 & Posma Sorimuda & Motivator 1 & SampahQu \\
3 & Ahmad & Motivator 2 & SampahQu \\
4 & Helena Juliana Kristina & Admin kelas online dan & Teknik Industri UNTAR \\
& & praktik & Teknik Elektro UNTAR \\
\hline
\end{tabular}




\section{Tabel 2}

\begin{tabular}{lcccc}
\multicolumn{5}{l}{ Deskripsi Partisipan } \\
\multicolumn{1}{l}{ No } & Nama Partisipan & Komunitas & Keterangan Pendidikan & Umur (thn) \\
\hline 1 & Allen & BS Daffodil & D3 Desain & 50 \\
2 & Arif sumarno & BS Daffodil & SMA & 31 \\
3 & Jalil & BS Daffodil & SLTA & 35 \\
4 & Mamat & SampahQu & SMP & 39 \\
5 & Shafly & SampahQu & Mahasiswa ekonomi & 20 \\
6 & Ryan & SampahQu & Mahasiswa Teknik elektro & 20 \\
7 & Ammirul & SampahQu & SMK bengkel mobil & 20 \\
\hline
\end{tabular}

\section{Tabel 3}

\section{Contoh Jadwal Pertemuan Kelas}

\begin{tabular}{ll}
\hline Pertemuan ke & \multicolumn{1}{c}{ Keterangan } \\
\hline Pertemuan 1 & Jadwal Pertemuan online (video call wa) Minggu, 7 Maret 2021 Pk. 14.00 - \\
& 15.00. kapasitas video call wa 8 org (tiap pengajar bergantian masuk keluar, \\
& dipandu admin). \\
& Susunan Acara: \\
& 1. Perkenalan partisipan, penjelasan singkat PKM kelas bengkel SampahQu, \\
& pengecekan hasil kuesiner awal (Helena), durasi 15 menit. \\
& 2. Motivator 1: Posma, durasi 10 mnt \\
& 3. Pengajar Utama: Rosehan, durasi 20 mnt \\
& 4. Motivator 2: Ahmad, durasi 15 mnt \\
& Kelas Praktik: Minggu, 14 Maret 2021, Pk. 14.00 sd 17.00 \\
Pertemuan 2 & Pos 15416. \\
& Materi yang dipelajari: Mempelajari fisik, kegunaan, cara kerjanya, \\
& Mempelajari kerusakan, Membuat keputusan; perbaikan atau kanibal, \\
& Pertimbangan sisi ekonomis perbaikan atau kanibal. \\
& Objek barang rongsok yang dipelajari: rice cooker, setrika, pemanas air, \\
& Speaker subwoofer simbada, mixer cosmos, Speaker bluetooth merk Advance, \\
& Kipas angin, merk Cosmos, Blender, merek Miyako. \\
& Part yang khusus dipelajari: kabel. Pengajar: Rosehan dan Suraidi \\
\hline
\end{tabular}

\section{HASIL DAN PEMBAHASAN}

Macdonald dan Goulet (2014) mengatakan bahwa pengetahuan dapat dipahami sebagai pengalaman, pemahaman kontekstual, informasi atau wawasan yang memiliki nilai tambah berdasarkan kerangka pemahaman yang ada di benak individu atau kelompok dan harus dikelola dengan sendirinya di hadirkan dalam bentuk pengetahuan eksplisit. Kapasitas bahasa antar individu juga dipandang sebagai salah satu faktor yang mempengaruhi pelaksanaan transfer pengetahuan khususnya antar individu (Nguyen \& Burgess, 2014). Berdasarkan informasi inilah, maka tim PKM membuat kegiatan kelas online pertemuan pertama untuk menyamakan persepsi antara tim PKM dan tim partisipan kelas bengkel SampahQu, agar semua orang yang terlibat mempunyai pemahaman yang sama dalam aktivitas kelas praktik saat mempelajari fisik, kegunaan, cara kerja barang/part/alat/perkakas, mempelajari kerusakan, membuat keputusan perbaikan atau kanibal, dan pertimbangan sisi ekonomis perbaikan atau kanibal. Dengan memiliki kesepahaman yang sama, diharapkan interaksi yang terjadi dalam kelas praktik nantinya bisa berjalan cukup lancar, dikarenakan tingkat pendidikan, pengetahuan dan pengalaman tiap partisipan berbeda -beda. Dan hal ini dapat menjadi hambatan dalam transfer pengetahuan.

Hasil kuesioner awal menjelaskan bahwa 5 orang partisipan sudah bekerja dibidang persampahan mulai dari 1 tahun sampai 10 tahun, sedangkan 2 orang partisipan belum pernah bekerja dibidang persampahan, sehingga tidak punya pengetahuan mengenai sampah barang rongsok. Motivasi ke- 
lima partisipan yang bekerja dibidang pengelolaan sampah juga bervariasi, mulai dari sebagai pekerjaan utama, pekerjaan sampingan, pekerjaan kemasyarakatan, dan pekerjaan sosial karena bergerak untuk mengedukasi masalah sampah di masyarakat. Partisipan berpendapat yang terpikirkan oleh mereka terhadap sampah barang rongsok sebelum ada kegiatan kelas bengkel SampahQu adalah sampah barang rongsok cukup disetorkan saja ke bank sampah, dikumpulkan, dipilah-pilah dan ditampung karena ada nilai jualnya, dan sekaligus mendukung program daur ulang. Ada juga partisipan yang yakin bahwa sampah barang rongsok bisa diperpanjang masa pakai atau untuk pemanfaatan yang lain atau reuse. Para partisipan yang sudah mencoba memanfaatkan sampah barang rongsok untuk reuse, hanya menggunakan alat-alat sederhana seperti obeng, tang, baterai, kabel power, multimeter, cutter, palu, kunci inggris, dan dengan cara belajar otodidak sebisa mereka mengolahnya agar barang rongsok yang masih bagus dapat hidup kembali. Kendala yang dihadapi partisipan dalam mengolah sampah barang rongsok adalah kurangnya alat dan ilmu.

Pengalaman partisipan akan sampah barang rongsok-pun bermacam-macam, mulai dari mampu mengetahui pengelompokan jenis sampah dan nilai ekonomi dari jenis sampah barang rongsok, mengetahui bahwa banyak barang rongsok yang masih bisa dimanfaatkan dan berguna, partisipan masih coba-coba mengolah sampah barang rongsok dan ternyata banyak kesulitan ditemui dalam prosesnya, mengetahui beberapa rongsok, sebenarnya masih berfungsi, tapi karena sudah ketinggalan model, dibuang/ditimbang saja oleh yang punya barang, punya pengetahuan bisa memilah barang rongsok yang bisa dijual dengan harga tinggi. Harapan partisipan dengan mengikuti kelas bengkel SampahQu, juga bermacam-macam, mulai dari mau membantu meminimalisir pembuangan barang rongsok ke TPA, berharap agar barang yang rusak bisa di manfaatkan kembali, ingin ada nilai ekonomis dari sampah rongsokan, mau membuka mata masyarakat bahwa sampah barang rongsok masih bisa di manfaatkan, didaur ulang dalam bentuk lain atau di perbaiki kembali/ difungsikan lagi, dan jadi bermanfaat bagi orang-orang yang perlu. Partisipan juga berharap dapat mempunyai tempat atau komunitas yang bisa diajak berdiskusi untuk mengelola sampah barang rongsok.

Hasil Kuesioner evaluasi menunjukan bahwa setiap partisipan sudah mencoba belajar menangani permasalahan 2-3 barang rongsok pada setiap pertemuan kelas praktik. Semua partisipan mengakui bahwa pengetahuan mereka akan barang rongsok sudah bertambah sejak pertemuan kelas 1,2, 3 dan 4. Tanggapan yang diberikan partisipan, dari kegiatan kelas bengkel SampahQu, mereka mendapatkan pengetahuan sebagai berikut:

$\checkmark$ Barang atau alat yang menggunakan listrik ternyata bisa diperbaiki jika rusak.

$\checkmark$ Menjadi paham fungsi multimeter, cara mengecek kabel putus, dan sedikit mengetahui tentang alat-alat listrik dan fungsinya.

$\checkmark$ Banyak barang rosok yang ternyata masih bisa diperbaiki dan mempunyai nilai ekonomi yang lebih daripada langsung ditimbang jadi sampah.

$\checkmark$ Mencari masalah atau kerusakan barang rongsok secara praktis, dan perbaiki dengan biaya seirit mungkin.

$\checkmark$ Perbaiki barang yang masih bisa berfungsi, karena nilai jualnya lebih tinggi.

$\checkmark$ Jika membuka asal -asalan pada suatu mesin, ada kemungkinan mesin tidak akan bisa diperbaiki lagi.

$\checkmark$ Bisa mengetahui atau mendeteksi barang yang rusak dan menggabungkan dengan alat atau barang lain yang masih bagus, seperti misalnya kabel.

$\checkmark$ Mengecek kelayakan kabel dan mengecek bagian dalam rangkaian elektronik, untuk mengetahui apakah part tersebut sudah tidak bisa digunakan lagi, sebelum memutuskan mau membuka dan mengambil isinya yang masih bisa digunakan di alat lain untuk 
mengkanibalkan untuk alat yang lain dengan spesifikasi yang sama seperti alat yang sudah diambil atau dilepas komponen atau part bagian dalam barang rongsok.

$\checkmark$ Bisa mengecek kelayakan alat tersebut dan memperbaiki bagian yang mudah, seperti ganti kabel dan bagian yang mudah lainnya dengan biaya yang murah.

Hasil kuesioner evaluasi juga menunjukan bahwa partisipan merasa diperlukan kerja tim untuk menangani sampah barang rongsok, hal ini dikarenakan keterbatasan ilmu, dan merasa perlunya saling mengingatkan antar teman, juga untuk saling bertukar pikiran, karena bisa membagi pengalaman dari masing-masing anggota tim.

\section{KESIMPULAN DAN SARAN}

Telah berhasil dibuat suatu kegiatan PKM transfer pengetahuan nilai barang rongsokan untuk komunitas SampahQu, dalam suatu program yang diberi nama "Kelas Bengkel SampahQu". Transfer pengetahuan sudah terlaksana, hal dikarenakan kegiatan PKM disusun dengan strategi sistematis dan bertujuan untuk mensukseskan proses transfer pengetahuan tersebut, melalui usaha membangun motivasi internal partisipan, bahwa sampah punya nilai yang tinggi kalau bisa dikelola dengan benar, sekaligus mendukung program reuse dan recovery. Interaksi adalah faktor penting untuk pelaksanaan proses transfer pengetahuan dalam PKM ini, di mana hubungan antara individu dibangun untuk mengurangi batasan dan hambatan dalam mentransfer pengetahuan. Keberhasilan transfer pengetahuan dapat dicapai hanya jika hubungan saling percaya antara partisipan, mitra dan tim PKM tercipta. Partisipan juga berharap dapat mempunyai tempat atau komunitas yang bisa diajak berdiskusi untuk mengelola sampah barang rongsok. Partisipan merasa diperlukan kerja tim untuk menangani sampah barang rongsok, hal ini dikarenakan keterbatasan ilmu, dan merasa perlunya saling mengingatkan antar teman, juga untuk saling bertukar pikiran, karena bisa membagi pengalaman dari masing-masing anggota tim.

\section{Ucapan Terima Kasih (Acknowledgement)}

1. Kepada Mitra SampahQu Bp Posma untuk kerjasamanya dalam mewujudkan kegiatan PKM ini.

2. Kepada LPPM UNTAR yang telah membiayai kegiatan PKM ini.

\section{REFERENSI}

Standtek, A. (2017). Kebijakan produksi bersih. http://www.menlh.go.id/kebijaksanaan-produksibersih-di-indonesia

Blumenberg, S., Wagner, H.-T., and Beimborn, D. (2009). Knowledge transfer processes in IT outsourcing relationships and their impact on shared knowledge and outsourcing performance. International Journal of Information Management, 29(5), 342-352.

Susan, C. \& Myers, G. (2014). Psikologi konservasi: memahami dan meningkatkan kepedulian manusia terhadap alam. Pustaka Pelajar.

Gujarat. (2016). Cleaner production centre. Cleaner Production in Household.

Asroel, H. (2019). Bank sampah: masalah dan solusi. CV. Syahadah Creative Media.

Helena, K. J. (2014). Program Pemberdayaan Bank Sampah Masyarakat Berkelanjutan sebagai Salah Satu Penggerak Terwujudnya Reverse Logistic Manajemen Rantai Pasok Manufaktur Berkelanjutan, Seminar Nasional Teknologi dan Sains, Fakultas Teknik Universitas Tarumanagara.

Martinkenaite, I. (2012). Antecedents of knowledge transfer in acquisitions. Baltic Journal of Management, 7(2), 167-184.

Namias, J. (2013). The Future of electric waste recycling in the United States: obstacles and domestic solutions. Columbia University. 
Nguyen, T., \& Burgess, S. (2014). A case analysis of ICT for knowledge transfer in small businesses in Vietnam. International Journal of Information Management, 34(3), 416-421.

Parent, M. M., MacDonald, D., \& Goulet, G. (2014). The theory and practice of knowledge management and transfer: The case of the Olympic Games. Sport Management Review, 17(2), 205-218.

Arief, S. (2018). Keynote speech Kepala Seksi Pemantauan Direktorat Pegelolaan Sampah pada Kementerian Lingkungan Hidup dan Kehutanan Republik Indonesia, rekaman suara pada Seminar "winning the future, today ", yang diadakan GAPMMI dan Tetra Pak Indonesia, Sheraton Hotel Gandaria City Jakarta.

Djajadiningrat, S. J., Hendriani, Y. \& Famiola, M. (2014). Ekonomi hijau. Rekayasa Sains. 